\title{
Retraction Note: Numerical simulation of sea surface temperature based on big data and calculation of economic effect of import trade
}

Yan $Y u^{1}$

Published online: 1 December 2021

(c) Saudi Society for Geosciences 2021

Retraction Note: Arabian Journal of Geosciences (2021) 14: 1665 https://doi.org/10.1007/s12517-021-08015-0

The Editor-in-Chief and the Publisher have retracted this article because the content of this article is nonsensical. The peer review process was not carried out in accordance with the Publisher's peer review policy. The author has not responded to correspondence regarding this retraction.

The original article can be found online at https://doi.org/10.1007/ s12517-021-08015-0

Yan $\mathrm{Yu}$

asxiaobei01@163.com

1 School of Management, Anshan Normal University, Anshan 114007, Liaoning Province, China 